\title{
COMPUTERIZING A RULE-BASED EXPERT SYSTEMS FOR DYNAMIC SCHEDULING IN BATCH PRODUCTION
}

\author{
Sami Salah Abdel Rahman \\ $\mathrm{PhD}$ Researcher \\ Department of Mechanical Engineering \\ Faculty of Engineering \& Technology, Nile \\ Valley University, Atbara, river Nile, Sudan.
}

\begin{abstract}
In the production factories they are working according to the balanced scorecard (BSC) approach, so they have strategic phases every phase has a duration of five years. Every phase has a strategic plan that divided into yearly plan (operation plan) and this operation plan also divided into monthly, weekly and daily plans. If there is no interruption for these plans the supply of raw materials, production procedures, maintenance and delivery date will go smooth and everything will be under control, but because the products have special needs from the customer, sometimes urgent orders are received and corrupting the workflow. Also sometimes the suppliers send raw materials too late due to some difficulties. Internally also there are some difficulties such as time for maintenance, rejected products, downtime ... etc. so the needs become top urgent and has to be scheduled using smart tools.

This research will assist to solve these problems according to the rule-based systems and will treat all interruptions and smoothing the workflow, easing due date determination, optimizing resources utilization.
\end{abstract}

Keywords: - Dynamic scheduling, Expert systems, Batch Production Factories, Computerizing, Rule based.

\section{INTRODUCTION}

Multi-products factories or batch production factories are mostly facing many difficulties resulting in delaying of the delivery due date. These difficulties will arise up if there are urgent requirements on uncertain time. Resources, such as machines, materials, manpower, time ... etc. are limited or otherwise no need for planning or scheduling if all resources are not limited. So process planning and scheduling are required to organize the production process and the dynamic scheduling will has paramount importance since its dealing with strategic products sometimes have uncertain orders, quantities, or ordering times and may be all unplanned orders are top urgent.

Artificial intelligent (Rule-based expert system) is a useful tool that can help in the dynamic scheduling for

\author{
M.I.Shukri \\ Professor \\ Department of Mechanical Engineering \\ Faculty of Engineering \& Technology, Nile \\ Valley University, Atbara, river Nile, Sudan.
}

Multi-products factories and can be computerized to organize production procedures of raw materials orders to products delivery and the determination of due dates

Management's desire to be more competitive and to increase profits through manufacturing. Customer responsiveness, increased output, lower manufacturing costs, better quality, short cycle times, bottleneck control and operational predictability, among many other themes, are hot issues on manager's minds. The management of manufacturing processes is a complex problem that's objective is to sell goods and services to the marketplace, through internal production resources and supplier agreements and capabilities. It is therefore advisable to structure the solution of the problem hierarchically, considering different aggregation levels of information and decisions, Figure 1.

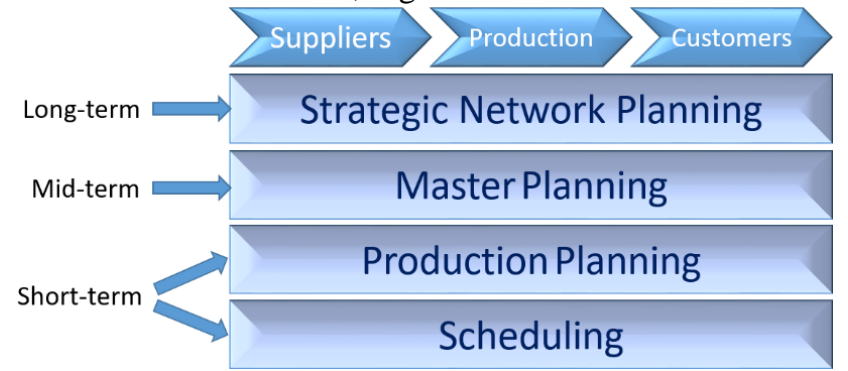

Fig. 1 Production planning management hierarchy [Kumar et al. (2008)]

Production Types

"(On www.bbc.co.uk/schools) there are four main types of industrial production methods:

1. One-off production is when only one product is made at a time.

2. Batch production is when a small quantity of identical products are made.

3. Mass production is when hundreds of identical products are made, usually on a production line.

4. Continuous flow production is when many thousands of identical products are made. The difference between this and mass production is that the production line is kept running 24 hours a day, seven days a week to maximize production and eliminate the extra costs of starting and 
stopping the production process. The process is highly automated and few workers are required".

\section{Batch Production}

"Kumar et al. (2008) Batch production is defined by American Production and Inventory Control Society (APICS) "as a form of manufacturing in which the job passes through the functional departments in lots or batches and each lot may have a different routing." It is characterized by the manufacture of limited number of products produced at regular intervals and stocked awaiting sales. Batch production system is used under the following circumstances:

1. When there is shorter production runs.

2. When plant and machinery are flexible.

3. When plant and machinery set up is used for the production of item in a batch and change of set up is required for processing the next batch.

4. When manufacturing lead time and cost are lower as compared to job order production".

\section{Scheduling}

"HERRMANN (2006) Scheduling is defined as "the timing of all operations with a view to insuring their completion when required." The scheduling personnel determined which specific worker and machine does which task. However, foremen remained on the scene. In some shops, the shop foremen, who should have more insight into the qualitative factors that affect production, were responsible for the detailed assignments".

\section{Scheduling Challenges}

"(On www.netronic.de/whitepaper) Production scheduling is an essential process of every manufacturing company. It has an immediate impact both on the top and the bottom line of any manufacturer. The complexity of both supply and demand networks and of production processes has been ever increasing. Hence, production scheduling seems to always face one or more of the below challenges figure 2 .

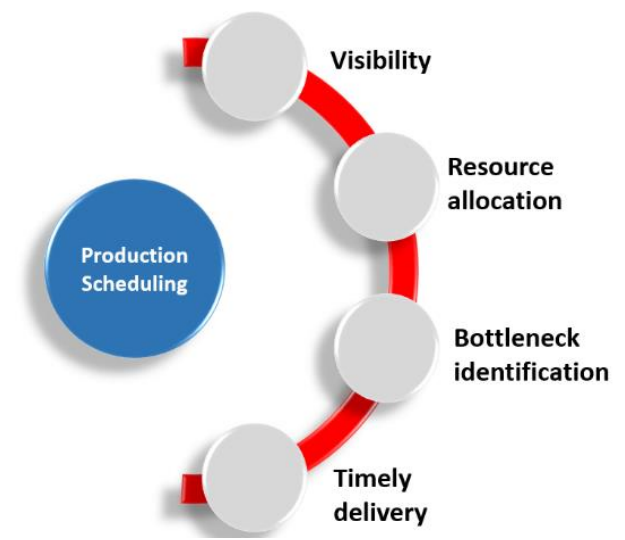

Fig. 2 Scheduling Challenges [www.netronic.de/whitepaper]

Many initiatives had been started to address these challenges. Independent of how sophisticated they are, all of them share one element. They all include a graphical planning board to visualize the production plan:

1. Increase Production Planning Visibility

Production planners need to always understand what is happening at the shop floor at any given time. If they do not have proper visibility, they cannot identify problems and cannot take counter measures in time. Typical questions requiring visibility are:

a. Will my production order be completed in time?

b. How is my resource utilization?

c. What is the status of any production order or operation?

2. Optimized Resource Allocation With A Planning Board

The planning board visualizes which operation had been allocated to which resource. It also shows free resources and often also the degree of capacity utilization. They are interactive and allow the planner to intuitively change the resource allocation by drag and drop operations.

3. Bottleneck Identification

If the production planning application is based on a proper Gantt chart tool, it includes a histogram to visualize the utilization of all available resources and hence the manufacturing planner can identify the bottleneck immediately. It is recommended to also provide a planning board view that shows all resources histograms on one view so that the planner identifies bottlenecks as well as underutilizes capacities.

4. Keeping Delivery Dates With Gantt Diagrams One key driver of customer satisfaction is the ontime delivery. With a visual production schedule, manufacturing companies are able to make realistic delivery time commitments to their customers".

\section{Dynamic Scheduling}

"HERRMANN (2006) dynamic scheduling does not create production schedules. Instead, decentralized production control methods dispatch jobs when necessary and use information available at the moment of dispatching. Sometimes dynamic scheduling schemes are called on-line scheduling or reactive scheduling. Such schemes use dispatching rules or other heuristics to prioritize jobs waiting for processing at a workstation or waiting to be moved by a material handling vehicle. In some facilities, pull production control schemes such as Kanban or constant work-inprocess (CONWIP) are used instead of scheduling".

"(On en.m.wikipedia.org) Scheduling is the process of absorbing the effect of real-time events, analyzing the current status of schedule, and automatically modifying the schedule with optimized measures in order to mitigate disruptions.

In the real world, however, manufacturing systems face uncertainty due to unexpected events occurring on 
the shop floor. Machines break down, operations take longer than anticipated, personnel do not perform as expected, urgent orders arrive, others are cancelled, etc. These disturbances render the ongoing schedule infeasible. In such case, a simple approach is to collect the data from the shop floor when the disruption occurs and to generate a new schedule from scratch".

\section{Scheduling Hierarchy}

"Lindholm et al. (2013) the structure depicted in Figure 3 is suggested for scheduling and disturbance management. The production scheduling layer in the figure produces a production schedule based on information on orders and forecasted orders, and the detailed production scheduling takes care of disturbances in production".

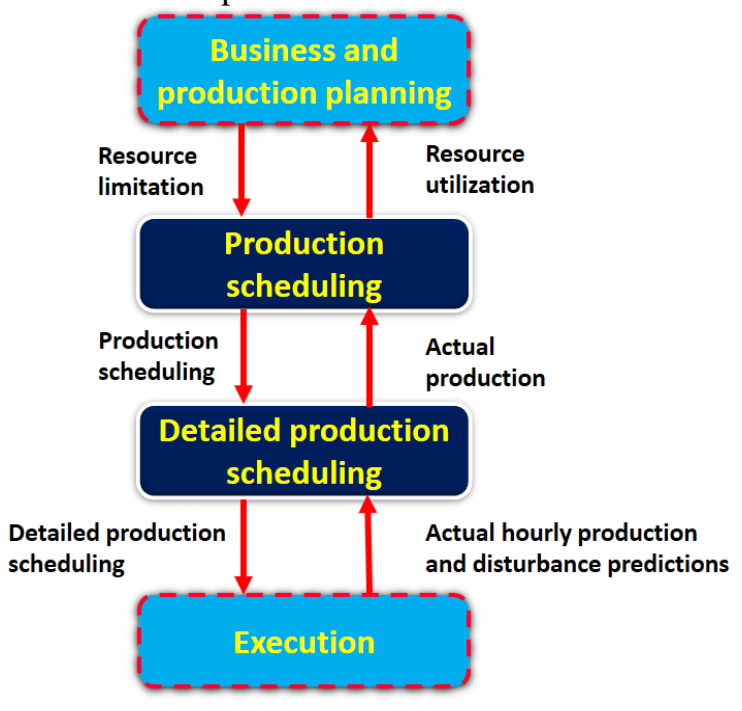

Fig. 3 Suggested scheduling hierarchy [Lindholm et al. (2013)]

\section{Rule-Based Expert Systems}

"Coppin (2004) Rule-based systems or production systems are computer systems that use rules to provide recommendations or diagnoses, or to determine a course of action in a particular situation or to solve a particular problem. A rule-based system consists of a number of components:

1. a database of rules (also called a knowledge base)

2. a database of facts

3. an interpreter, or inference engine

In a rule-based system, the knowledge base consists of a set of rules that represent the knowledge that the system has. The database of facts represents inputs to the system that are used to derive conclusions, or to cause actions. The interpreter, or inference engine, is the part of the system that controls the process of deriving conclusions. It uses the rules and facts, and combines them together to draw conclusions".

"Benyoucef et al. (2010) Expert systems are widely used in most of the industrial applications. Manufacturers may definitely exploit advantages of this technology for their own businesses. Expert systems make it possible to create intelligent software systems capable of solving problems in the same way as human experts would do when facing the same problems. Similarly, to human experts, they utilize their knowledge, experience and talents. This is possible when respective knowledge is stored in a specific format understandable to the computer. The knowledge, which is represented in machine-readable format, is stored in so-called knowledge bases. It is utilized by expert systems for a decision-making process similar to that of a human being in order to produce solutions to the problems. Figure 4 indicates basic components and architecture of an expert system. Each component is briefly explained below".

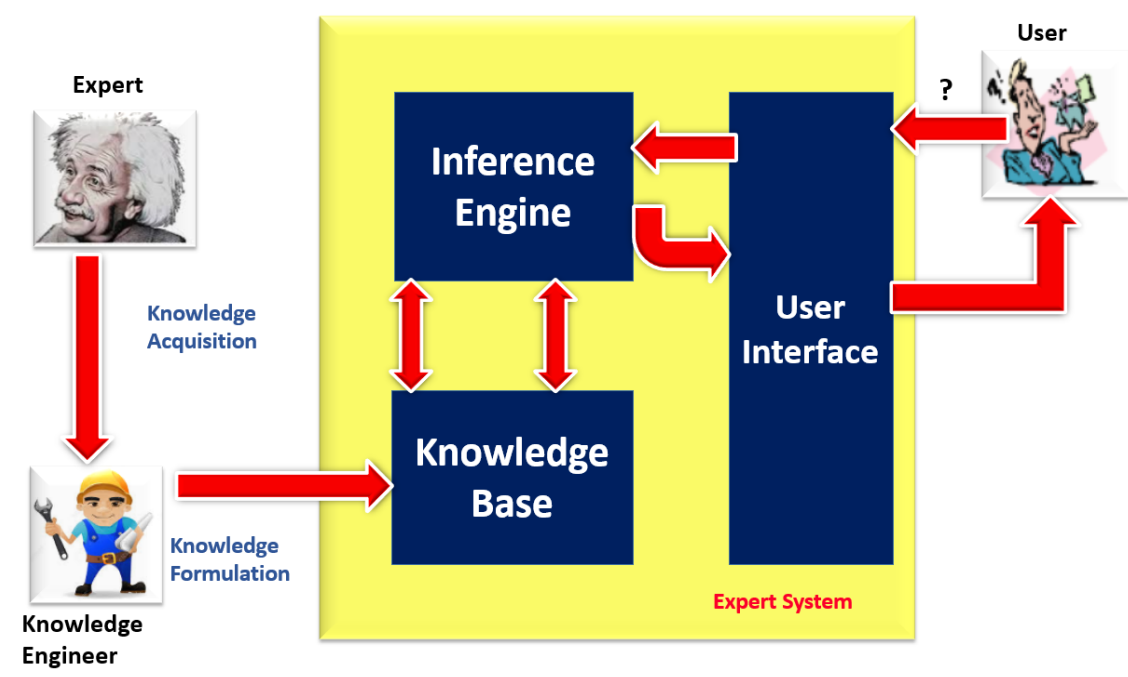

Fig. 4 Components of an expert system. [www.guru99.com/expert-systems]

\section{How do experts think?}

"Negnevitsky (2005) The human mental process is internal, and it is too complex to be represented as an algorithm. However, most experts are capable of expressing their knowledge in the form of rules for problem solving. 


\section{International Journal of Engineering Applied Sciences and Technology, 2020 \\ Vol. 5, Issue 2, ISSN No. 2455-2143, Pages 78-86 \\ Published Online June 2020 in IJEAST (http://www.ijeast.com)}

These statements represented in the IF-THEN form are called production rules or just rules. The term 'rule' in AI, which is the most commonly used type of knowledge representation, can be defined as an IFTHEN structure that relates given information or facts in the IF part to some action in the THEN part. A rule provides some description of how to solve a problem. Rules are relatively easy to create and understand". Expert Systems Process
"BADIRU ADEDEJI B. \& CHEUNG JOHN Y. (2010) Figure 5 presents the hierarchy of topics of expert systems. The strategic process is recommended for anyone venturing into the technology of expert systems from the standpoint of training, research, or applications. A basic understanding of the basic concepts of expert systems technology is essential to getting the most out of expert systems".

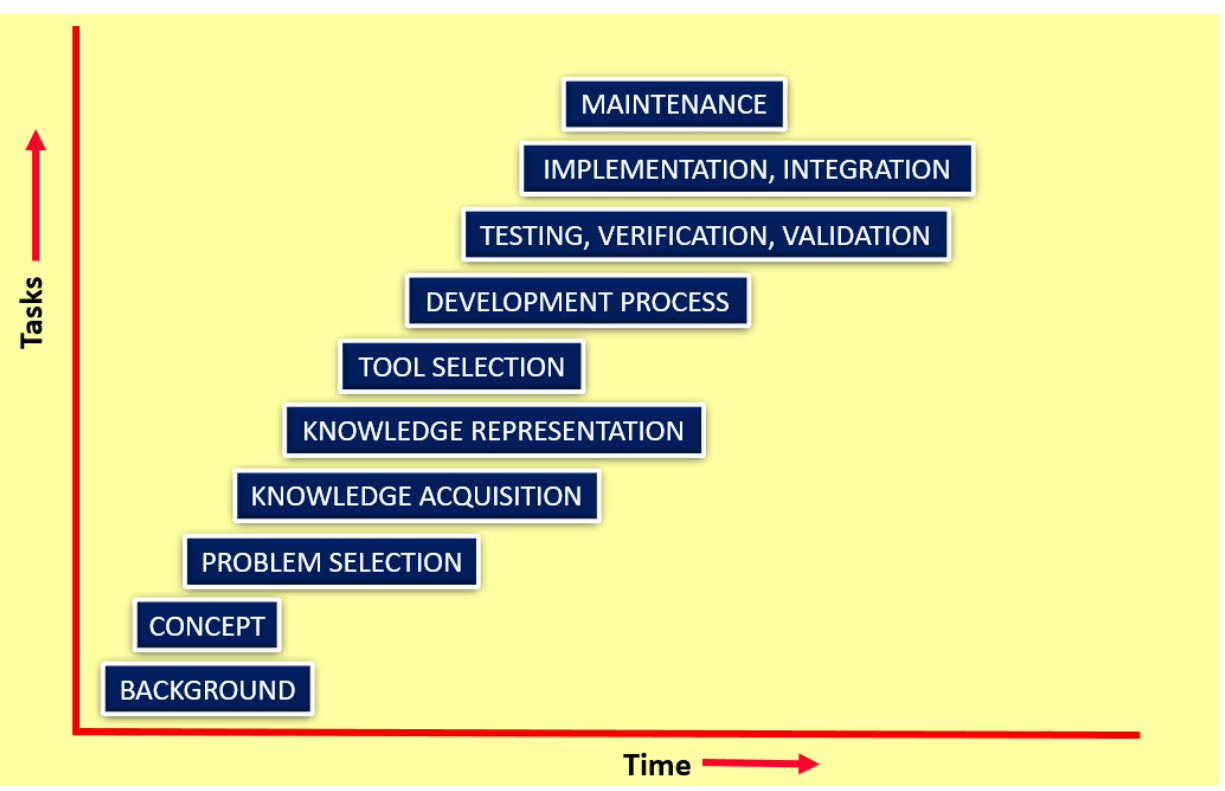

Fig. 5 Hierarchy of expert systems development process. [slideshare.net/imanog/expert-systems]

\section{The Need for Expert Systems}

"(On slideshare.net/imanog/expert-systems) Expert systems are necessitated by the limitations associated with conventional human decision-making processes, including:

1. Human expertise is very scarce.

2. Humans get tired from physical or mental workload.

3. Humans forget crucial details of a problem.

4. Humans are inconsistent in their day-to-day decisions.

5. Humans have limited working memory.

6. Humans are unable to comprehend large amounts of data quickly.

7. Humans are unable to retain large amounts of data in memory.

8. Humans are slow in recalling information stored in memory.

9. Humans are subject to deliberate or inadvertent bias in their actions.

10. Humans can deliberately avoid decision responsibilities.

11. Humans lie, hide, and die.

Coupled with these human limitations are the weaknesses inherent in conventional programming and traditional decision-support tools. Despite the mechanistic power of computers, they have certain limitations that impair their effectiveness in implementing human-like decision processes. Conventional programs:

1. Are algorithmic in nature and depend only on raw machine power

2. Depend on facts that may be difficult to obtain

3. Do not make use of the effective heuristic approaches used by human experts

4. Are not easily adaptable to changing problem environments

5. Seek explicit and factual solutions that may not be possible

\section{Benefits of Expert Systems}

Expert systems offer an environment where the good capabilities of humans and the power of computers can be incorporated to overcome many of the limitations. Expert systems:

1. Increase the probability, frequency, and consistency of making good decisions

2. Help distribute human expertise

3. Facilitate real-time, low-cost expert-level decisions by the non-expert

4. Enhance the utilization of most of the available data

5. Permit objectivity by weighing evidence without bias and without regard for the user's personal and emotional reactions

6. Permit dynamism through modularity of structure 
7. Free up the mind and time of the human expert to enable him or her to concentrate on more creative activities

8. Encourage investigations into the subtle areas of a problem".

\section{Computerization}

"(On en.wikipedia.org/wiki/Computerize $)$ can be defined as follows:

1. Computerization: equipping something with or the usage of and associated automation by computers and software

2. Business process reengineering that converts a manual process into one done by a computer

3. Equipping with a general purpose computer, embedded computer, or computer system

4. Inputting data (computing) into computers

5. Digitizing information for computers

6. Creating computer-generated content

\section{Programming}

"Felleisen et al. (2001) yet programming is more than just a vocational skill. Indeed, good programming is a fun activity, a creative outlet, and a way to express abstract ideas in a tangible form. And designing programs teaches a variety of skills that are important in all kinds of professions: critical reading, analytical thinking, creative synthesis, and attention to detail".

"Bjarne (2014) Programming is the art of expressing solutions to problems so that a computer can execute those solutions. Much of the effort in programming is spent finding and refining solutions. Often, a problem is only fully understood through the process of programming a solution for it.

Programming is more concrete than most forms of math, and therefore accessible to more people. It is a way to reach out and change the world ideally for the better. Finally, programming can be great fun".

\section{Problem Formulation}

This paper is concerning with a batch production factories (complex) having 14 products or more for each there is strategic plan, operation plan (one year plan) and many orders for these products. These plans are achieved by operating eight production lines which mean every line can produce more than one product if adapted to the required product. This complex has fixed resources and facing many difficulties resulting in the delaying of the produced batches due date.

The target is to use the rule base expert system approach so the complex will utilize its resources to meet the produced batches due date, reducing costs and maximizing the revenues.

The main difficulties are the upstream vendor difficulties, raw materials transportations, constant production lines capacities, growing annual orders, maintenance of the machines ... etc.

\section{Problem Identification}

"BADIRU ADEDEJI B. \& CHEUNG JOHN Y. (2010) The selection of an appropriate problem is extremely important and is a major factor in determining the success of expert systems. A good problem for expert systems is one that has the following characteristics:

1. The problem affects many people.

2. There is enough concern about the problem.

3. The problem is in a domain where experts are in short supply.

4. Solving the problem has the potential for significant time and cost savings.

5. There is a reliable and accessible source of knowledge to be acquired.

The identification of a problem may originate from any of several factors. Some of the factors are:

1. Internal needs and pressures

2. External motivation, such as market competition

3. Management requirement

4. Need for productivity improvement

5. Desire to stay abreast of the technology

6. Technological curiosity

7. Compliance with prevailing rules and regulations

8. Deficiencies in the present process"

\section{Overall Aims and Objectives:}

The overall aims and objectives of this paper are:

To Applying rule Base Dynamic Production Planning System for a Batch Production Factory in order to improve productivity. This expected to:

1. Maximizing the workflow output factories

2. Minimizing the interruption effects on the workflow

3. Giving accurate delivery time

4. reducing many overhead costs to minimum

5. Increasing customer satisfaction

\section{EXPERIMENTAL WORK}

As mentioned above this complex has about fourteen products produced on eight production lines and the complex has a very tight strategic and operational plans and also facing all types of disruptions (Capacity related disruptions, Orders related disruptions and Measurement of Data related disruptions) and all these disruptions has a great effects on the due date of any order. There is an idle time that can be used to manage the scheduled due date dynamically by adding working hours on days or shifts on weekends. This is the planning manager duties since he is very expert for these types of disruptions, but the process will take time and efforts and sometimes it will be very tedious if other machines has same or different disruptions. In this case the planning manager needs his expert and computer program to solve the disruption easily and in short time, but if his expert added or included in this computer program the dynamic scheduling or rescheduling can be done easily by everyone within the complex if he is absent. If the planning manager expertise formed in rule-based system using a computer software then the results will be same as experts people do because expert systems 


\section{International Journal of Engineering Applied Sciences and Technology, 2020 \\ Vol. 5, Issue 2, ISSN No. 2455-2143, Pages 78-86 \\ Published Online June 2020 in IJEAST (http://www.ijeast.com)}

make it possible to create intelligent software systems capable of solving problems in the same way as human experts would do when facing the same problems.

Software or computer program can be created using many types of computer programming languages and for this thesis visual Basic dot Net is used.

\section{Dynamic Scheduling Factors}

"Elrawi and Ellami (2016) there are many factors in Batch Production Factories for which dynamic scheduling is required to manage this disruptions which can be stated as follows:

1. Capacity Related Disruptions

a. Machine Capacity
i. Machine Breakdown
ii. Unplanned Maintenance
iii. Re-routing

b. Operator Capacity
i. Operator Absenteeism
ii. Strike

iii. Technical Skills and Capabilities

c. Tools Capacity

i. Unavailability of Tools

ii. Tools Sharing

iii. Unfit Tools

2. Orders Related Disruptions

a. Raw Materials Shortage

b. Rush Jobs

c. Jobs Cancellation

d. Change in Priority

e. Rework or Quality Problems

f. Continuous Arrival of Jobs

g. Due Dates Change (Delay or Advance)

3. Disruptions Related to Measurement of Data

a. Overestimation or Underestimation of Processing Time

b. Determination of Capacity Efficiencies

Fig. 6 shows all these dynamic scheduling disruptions factors hierarchically".

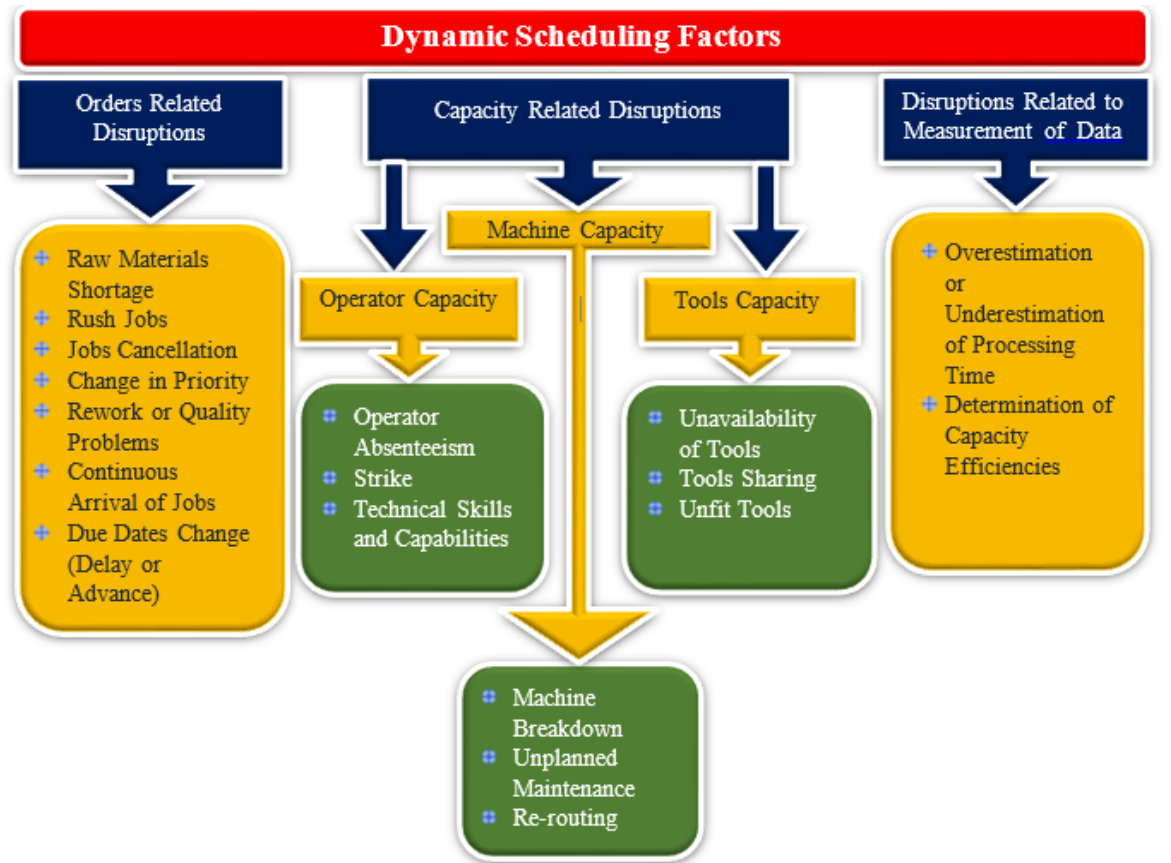

Fig. 6 Hierarchy of dynamic scheduling disruptions factors [Elrawi and Ellami (2016)]

\section{Program Structure}

This computer program is designed with Visual Basic Programming Language to cover all above factors, the program contains of three windows forms (Splash Screen, Dynamic Scheduling Main Form and General Form). Splash Screen is an introductory form and containing some definition about the program and its use, inputs and outputs.
The Dynamic Scheduling Main Form (Fig. 7) is reflecting the main three sections of the rescheduling factors (Capacity Related Disruptions, Orders Related Disruptions and Disruptions Related to Measurement of Data) and the user will select between these three sections according to the situation in the production lines. 


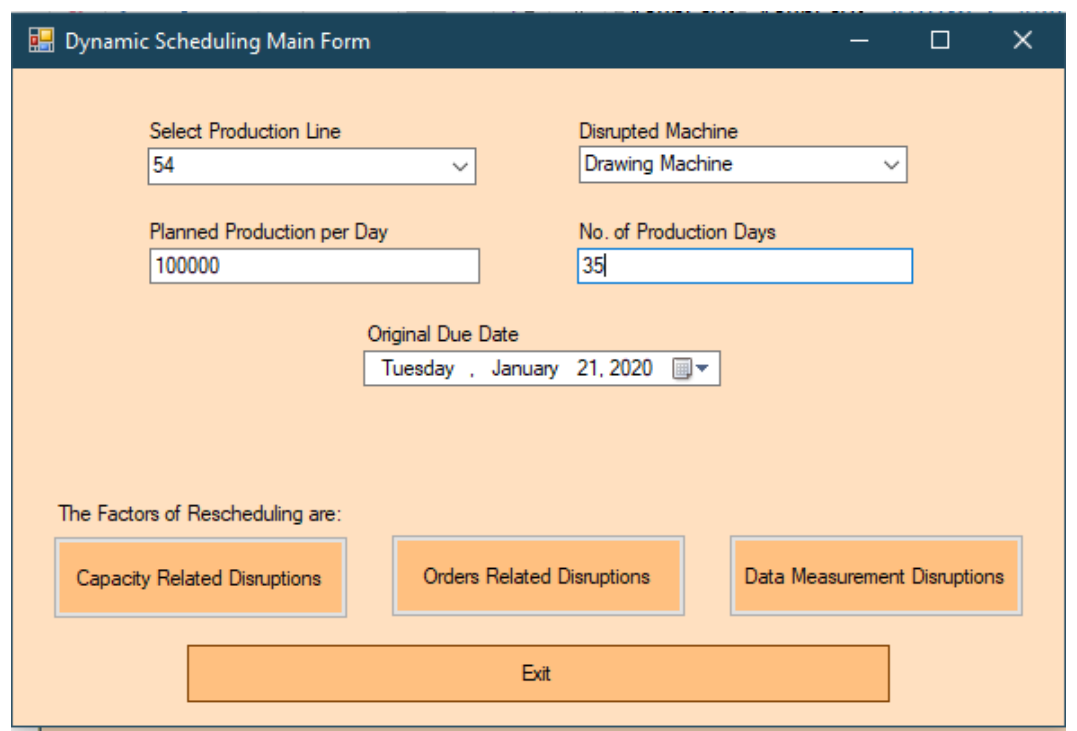

Fig. 7 the Dynamic Scheduling Main Form

After entering some information such as selection production line, disrupted machine, planned production per day, number of production days, and the original due date. Then the program can be followed as follow:

1. If Capacity Related Disruptions is selected -as an example for this paper- from Dynamic
Scheduling Main Form this will fire the General Form (Fig. 8) with its all types of capacity disruptions and the user will select which one is suitable according to the disruption in the production lines and the program can be run as follows:

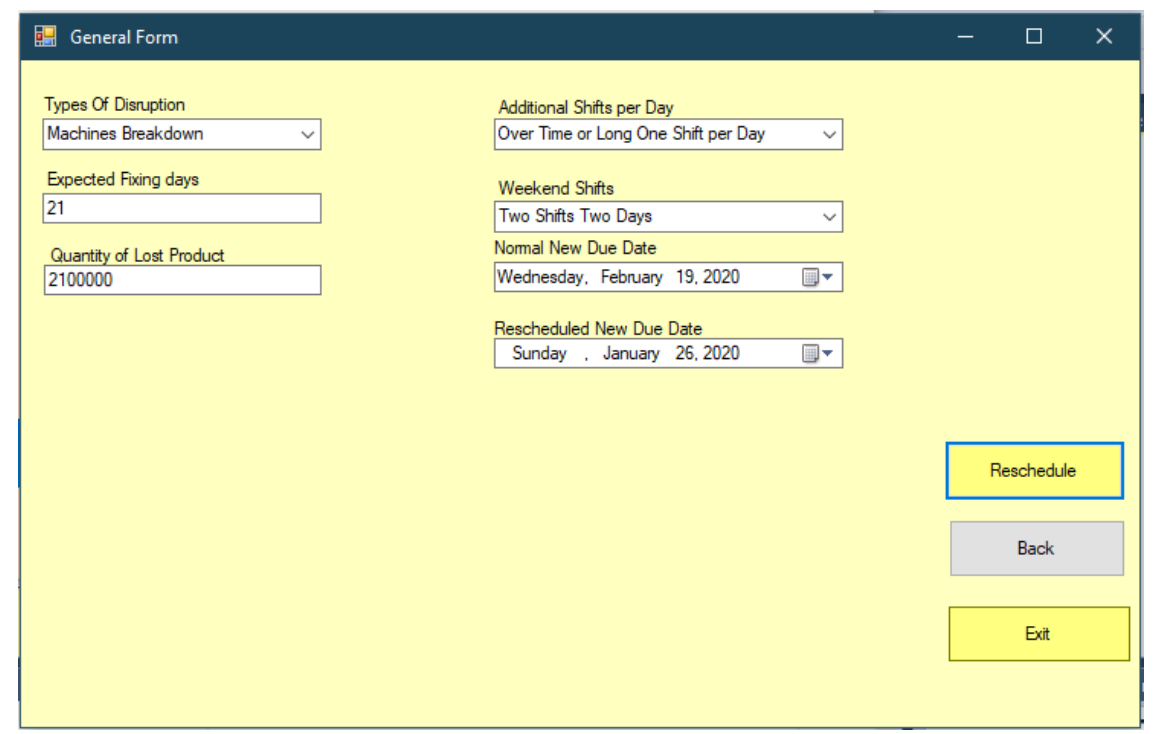

Fig. 8 General Form

If Machine Breakdown is selected (Fig. 9) from the types of disruption combo box (list), then many text boxes will appear such as Expected Fixing Days, Quantity of Lost Product and Normal New Due Date and user will fill the text box of the Expected Fixing
Days with the number of days required to fix the machine and it will resume the production. When clicking the Rescheduling Button the program will calculate the Normal New Due Date according to following equations 


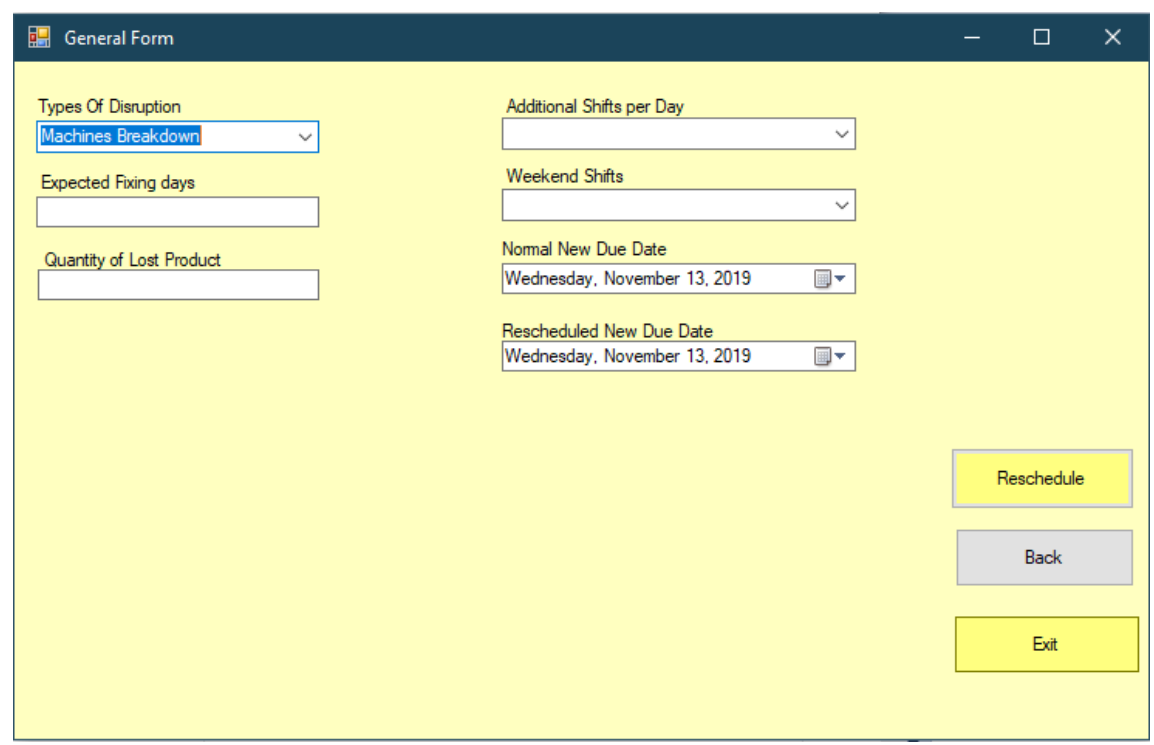

Fig. 9 Machine Breakdown is selected

With simple equations the production can be rescheduled according to the present situation of production lines disruption

1. quantity of Lost Product=Expected Fixing days* Planned Production per Day

2. Normal New Due Date $=$ Original Due Date + Expected Fixing days

\section{RESULTS AND DISCUSSION}

With this computer program the dynamic scheduling in this complex can be executed easily and every one of skill-shortages can do it for 14 or more products to be produced in 8 production lines and selecting the optimum situation and satisfying all customers and delivering the batches on the mentioned due date with the same resources, improving productivity, minimum costs and maximum revenues.

Rule based expert system approach is confirmed as applicable tool and helpful in the dynamic scheduling in the batch production factories, since the required results can be achieved in no time for -sometimes- a very complicated rescheduling. Other important results are the maximizing workflow, minimizing interruption effects on workflow and giving accurate delivery time at any time during production processes and the plans can be achieved easily with this ease of rescheduling (it's just some clicks).

\section{CONCLUSION}

Solving of this problem has the potential for significant time and cost savings and it's a reliable and accessible source of knowledge to be acquired, but still manufacturing processes need further works because the processes are longer than the covered areas inside the factories. The real start of these processes is at raw materials suppliers' situation, shipping, checking, storing . . . etc. so this program can be extended to cover this processes from the upstream vendor up to the customers products supply.

\section{REFERENCE}

1. http://www.bbc.co.uk/schools/gcsebitesize/design/ resistantmaterials/processindpracrevl.shtml (cited in 5/12/2017)

2. Kumar S. Anil \& N. Suresh, (2008) Production and Operations Management, New Age International, (pp 4-7)

3. HERRMANN JEFFREY W., (2006) HANDBOOK OF PRODUCTION SCHEDULING, springer, (pp 5 and 140-141)

4. http://www.netronic.de/whitepaper (cited in 5/1/2018)

5. Shiroma Patricia Jay, (1996) Efficient Production Planning and Scheduling An Integrated Approach with Genetic Algorithms and Simulation, Springer, $1^{\text {st }}$ edition,

6. https://en.m.wikipedia.org/wiki/Dynamic_priority _scheduling (cited in 5/1/2018)

7. Lindholm A., Giselsson P., Quttineh,N-H. Lidestam H., Johnsson C. and Forsman K., (2013) PRODUCTION SCHEDULING IN THE PROCESS INDUSTRY, 22nd International Conference on Production Research, (pp 1-2)

8. Coppin Ben, (2004) Artificial Intelligence Illuminated, JONES AND BARTLETT PUBLISHERS, (pp 243)

9. Benyoucef Lyes \& Grabot Bernard, (2010) Artificial Intelligence Techniques for Networked Manufacturing Enterprises Management, Springer, (pp 14-16)

10. https://www.guru99.com/expert-systems-withapplications.html (cited in 23/12/2019)

11. Negnevitsky, Michael, (2005) Artificial Intelligence, A Guide to Intelligent Systems, Pearson Education, Second Edition, 
12. BADIRU ADEDEJI B. \& CHEUNG JOHN Y.,( 2002) FUZZY ENGINEERING EXPERT SYSTEMS WITH NEURAL NETWORK APPLICATIONS, JOHN WILEY, (pp 13-14)

13. https://www.slideshare.net/imanog/expertsystems-48027401 (cited in 23/12/2019)

14. https://en.wikipedia.org/wiki/Computerize (cited in $5 / 12 / 2017$ )

15. Felleisen Matthias, Findler Robert Bruce, Flatt Matthew and Krishnamurthi Shriram, (2001)How to Design Programs An Introduction to Computing and Programming, MIT Press, (pp 8)

16. Bjarne Stroustrup, 2014, Programming Principles and Practice Using C++, Addison-Wesley, (pp xxv - xxvi)

17. Elrawi Maha and Ellami Ghassan, Operations Rescheduling Strategies, Policies, and Methods: A Philosophic Approach, (2016) Baghdad University, (Arabic language paper), (pp 6-7) 